\title{
Study of the Colourimetric and Photoluminescence Proprieties of Polyamide fiber
}

\author{
AHLEM GUESMI ${ }^{1,2 *}$ and NAOUFEL BEN HAMADI ${ }^{2,3}$ \\ ${ }^{1}$ Textile Engineering Laboratory, Higher Institute of Technological Studies of Ksar Hellal, \\ University of Monastir, Tunisia. \\ ${ }^{2}$ Al Imam Mohammad Ibn Saud Islamic University (IMSIU), College of Sciences, \\ Department of Chemistry, 11623 Riyadh, Saudi Arabia. \\ ${ }^{3}$ Laboratory of Synthesis Heterocyclic and Natural Substances, Faculty of Sciences of Monastir, \\ UM (University of Monastir), Boulevard of Environment, 5000 Monastir, Tunisia. \\ Corresponding author E-mail : bh_naoufel@yahoo.fr \\ http://dx.doi.org/10.13005/ojc/330520 \\ (Received: May 22, 2017; Accepted: June 20, 2017)

\begin{abstract}
This research work involves the synthesis, the characterization, and the dyeing application 4 was registered as the optimal $\mathrm{pH}$ value of dyeing polyamide fabrics with the synthesized dyes. The color depth as measured by the K/S value, the colorfastness to washing and light were also evaluated. Under UV exposure, intense emission of orange red was observed for dyed polyamide. Potential applications of this technology include protective clothing, textile-based sensors, and smart tagging.
\end{abstract} \\ of some reactive dyes between polyamide fibers. All the dyeing parameters have been studied, $\mathrm{pH}$
}

Keywords: polyamide; reactive dyes; dyeing; fastness; photoluminescent.

\section{INTRODUCTION}

Many works have been interested on the dyeing of nylon fibers and many classes of dyes have been used ${ }^{1,2}$. The presence of terminal amino groups in nylon fibers imparts substantivity towards anionic dyes, this made that coloration of nylon was usually achieved with acid dyes, but the major problem was related to their poor fastness properties ${ }^{3,4}$. For this reason, a specific interest has been focused on the dyeing of nylon with reactive dyes, and it was known that some reactive dyes, which were developed for cellulosic fibers, can be covalently fixed at the boil, to nylon at slightly acidic
$\mathrm{pH}$. Under these conditions, covalent bonds form between the dye and the amino groups of nylon, without the need for an alkaline fixation step ${ }^{5-9}$.

Photoluminescent polyamide fiber, that are now ubiquitous in our everyday life, have particularly attracted the attention of the scientific community these past few years due to potential important applications such as protective clothing, textile-based sensors, and smart tagging.

In the same way, we have developed the present study to elucidate the dependence between the dyeing results and the dye structure. The aim 
was the synthesis of a new series of reactive dyes and to test the effect of the presence of a withdrawing electron group in the dye structure on the dyeing results. The overall dyeing parameters of nylon with synthesized dyes have been studied and optimized.

\section{EXPERIMENTAL}

\section{Materials}

Infrared spectra were recorded on a Perkin-Elmer IR-197 spectrophotometer in KBr discs. NMR spectra were obtained with a Bruker AC 300 spectrometer operating at $300 \mathrm{MHz}$ for ${ }^{1} \mathrm{H}$ and at $75.47 \mathrm{MHz}$ for ${ }^{13} \mathrm{C}$ using TMS as the internal standard. Elemental analysis was performed with a Perkin-Elmer 240 B microanalyzer. Visible absorption spectra were recorded using a Phillips model PU 8700 UV/visible spectrophotometer. Mass spectra were recorded in ESI mode. Thin layer chromatography (TLC) was performed using aluminum plates coated with silica gel 60 F254 (Merck \& Co.) as stationary phase, and a mixture of isobutanol: n-propanol: ethyl acetate: water in the ratio 2:4:1:3 as mobile phase. The developed plates were visualized under both short and long wavelength ultraviolet light $(254 \mathrm{~nm}, 365 \mathrm{~nm})$.

\section{Methods}

Preparation of reactive dyes

A series of dyeing experiments were directed using three novel red orange reactive dyes listed in Table 1. Dyes from 1 to 3 , were prepared as described below.

\section{Synthesis of azo dyes 3a-c}

Scheme 1 represent the preparation route of azo dyes 3a-c. A solution of sodium nitrite (3.62 $\mathrm{g}, 0.058 \mathrm{~mol})$, in water $(20 \mathrm{ml})$, was added slowly to a mixture of aniline derivatives $(0.05 \mathrm{~mol})$, in water $(20 \mathrm{ml})$ and hydrochloric acid $(30 \%, 14.19 \mathrm{ml}, 0.125$ $\mathrm{mol}$ ), at $0-5^{\circ} \mathrm{C}$. After $30 \mathrm{~min}$. at $0-5^{\circ} \mathrm{C}$ and an acidic medium ( $\mathrm{pH}$ less than 2), excess nitrous acid was destroyed by adding sulphamic acid. The resulting solution of benzene diazonium chloride was added slowly to a solution of g-acid (1-hydroxy-7aminonaphthalene- 3-sulphonic acid) (11.9 g, 0.05 $\mathrm{mol}$ ), at pH 6-6.5. The mixture was stirred for $30 \mathrm{~min}$ at room temperature and at $\mathrm{pH} 6.5$. The solid product(1-hydroxy-2-arylazo-7-aminonaphthalene- 3-sulphonicacid) was collected and purified by dissolving in distilled water $(100 \mathrm{ml})$ and re-precipitating by slow addition of potassium chloride $(30 \% \mathrm{w} / \mathrm{v})$ to the stirred solution (Scheme 1).

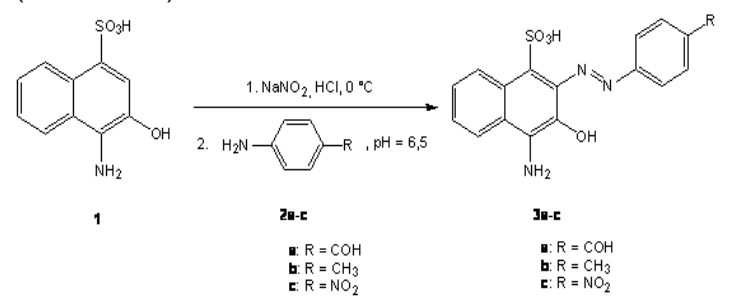

Scheme. 1. Synthesis of azo dyes 3a-c

\section{Structural study of azo dyes 3a-c}

Structures of all new compounds 3a-c have been elucidated by FT-IR, mass spectroscopy, elemental analyses, ${ }^{1} \mathrm{H}-\mathrm{NMR}$ and ${ }^{13} \mathrm{C}$-NMR measurements.

In IR spectra of azo dye 3b, structure was confirmed by functional group identification. Amino and alcohol group gave its peak at $3260 \mathrm{~cm}^{-1}$, and appearance of the weak absorption band at 1560 $\mathrm{cm}^{-1}$ was due to the stretching band of azo group.

In the ${ }^{1} \mathrm{H}-\mathrm{NMR}$ spectra of azo dye $3 \mathrm{~b}$, the four hydrogen atoms attached to the paradisubstituted ring gave an AA'BB' spin system.

\section{4-Amino-2-(4-formyl-phenylazo)-3-hydroxy- naphthalene-1-sulfonic acid 3a}

Solid Yield (55\%); m.p. $134-135{ }^{\circ} \mathrm{C}$. IR $(\mathrm{KBr}): v / \mathrm{cm}^{-1}=3250\left(\mathrm{NH}_{2}, \mathrm{OH}\right), 1730(\mathrm{C}=\mathrm{O}), 1550$ $(\mathrm{N}=\mathrm{N}) .{ }^{1} \mathrm{H}$ NMR (DMSO- $\left.d_{6}, 300 \mathrm{MHz}\right): \delta / \mathrm{ppm}: 9.12$ (s, $1 \mathrm{H}, \mathrm{C}=\mathrm{O}$ ), 7.40 and 7.83 (d, $4 \mathrm{H}, \mathrm{J}=8.7 \mathrm{~Hz}$, $\left.\mathrm{H}_{\text {arom }}\right), 7.31-7.39\left(\mathrm{~m}, 4 \mathrm{H}, \mathrm{H}_{\text {arom }}\right), 10.24\left(\mathrm{~s}, 2 \mathrm{H}, \mathrm{NH}_{2}\right)$, $11.35(\mathrm{~s}, 1 \mathrm{H}, \mathrm{OH}) .{ }^{13} \mathrm{C}$ NMR (DMSO- $d_{6}, 75.47 \mathrm{MHz}$ ): $\delta / \mathrm{ppm}=119.3,122.7,123.8,125.3,125.5,126.6$, $126.9,127.2,127.8,128.7,129.3,130.6,140.9$, 152.7, 185.9. Anal. Calcd for $\mathrm{C}_{17} \mathrm{H}_{13} \mathrm{~N}_{3} \mathrm{O}_{5} \mathrm{~S}: \mathrm{C}, 54.98$; $\mathrm{H}, 3.53 ; \mathrm{N}, 11.31 \%$. Found: C, C, 54.95; H, 3.55; N, $11.37 \%$.

\section{4-Amino-3-hydroxy-2-p-tolylazo-naphthalene-1- sulfonic acid $3 b$}

Solid Yield (90\%); m.p. $177-178{ }^{\circ} \mathrm{C}$. IR $(\mathrm{KBr}): v / \mathrm{cm}^{\prime 11}=3270\left(\mathrm{NH}_{2}, \mathrm{OH}\right), 1555(\mathrm{~N}=\mathrm{N}) .{ }^{1} \mathrm{H}$ NMR (DMSO- $\left.d_{6}, 300 \mathrm{MHz}\right): \delta / \mathrm{ppm}: 2.12\left(\mathrm{~s}, 3 \mathrm{H}, \mathrm{CH}_{3}\right), 6.98$ and $7.39\left(\mathrm{~d}, 4 \mathrm{H}, \mathrm{J}=8.7 \mathrm{~Hz}, \mathrm{H}_{\text {arom }}\right), 7.42-8.04(\mathrm{~m}, 4 \mathrm{H}$, $\left.\mathrm{H}_{\text {arom }}\right), 10.01\left(\mathrm{~s}, 2 \mathrm{H}, \mathrm{NH}_{2}\right), 11.58(\mathrm{~s}, 1 \mathrm{H}, \mathrm{OH}) \cdot{ }^{13} \mathrm{C}$ NMR (DMSO- $d_{6}, 75.47 \mathrm{MHz}$ ): $\delta / \mathrm{ppm}=21.51,114.31$, 
122.8, 123.6, 125.3, 126.5, 126.8 127.1, 127.6, 127.9, 129.3, 129.7, 139.8, 140.9, 149.5.Anal. Calcd for $\mathrm{C}_{17} \mathrm{H}_{15} \mathrm{~N}_{3} \mathrm{O}_{4} \mathrm{~S}$ : C, 57.13; $\mathrm{H}, 4.23 ; \mathrm{N}, 11.76$. Found: C, 57.16; H, 4.20; N, 11.81\%.

\section{4-Amino-3-hydroxy-2-(4-nitro-phenylazo)- naphthalene-1-sulfonic acid 3c}

Solid Yield (75\%); m.p. $146-147^{\circ} \mathrm{C}$. IR (KBr): $v / \mathrm{cm}^{\prime 1}=3260\left(\mathrm{NH}_{2}, \mathrm{OH}\right), 1560(\mathrm{~N}=\mathrm{N}) .{ }^{1} \mathrm{H}$ NMR (DMSO- $\left.d_{6}, 300 \mathrm{MHz}\right): \delta / \mathrm{ppm}: 7.21-7.98(\mathrm{~m}, 4 \mathrm{H}$, $\left.\mathrm{H}_{\text {arom }}\right), 8.21$ and $8.37\left(\mathrm{~m}, 4 \mathrm{H}, \mathrm{J}=7.8 \mathrm{~Hz}, \mathrm{H}_{\text {arom }}\right), 10.33$ (s, $\left.2 \mathrm{H}, \mathrm{NH}_{2}\right), 11.43(\mathrm{~s}, 1 \mathrm{H}, \mathrm{OH}) .{ }^{13} \mathrm{C}$ NMR (DMSO$\left.d_{6}, 75.47 \mathrm{MHz}\right): \delta / \mathrm{ppm}=119.3,120.1,123.2,123.6$, 124.2, 125.2, 126.3, 126.5, 127.1, 127.9, 128.7, 129.3, 140.3, 155.1. Anal. Calcd. for $\mathrm{C}_{16} \mathrm{H}_{12} \mathrm{~N}_{4} \mathrm{O}_{6} \mathrm{~S}$ : C, 49.48; H, 3.11; N, 14.43.Found: C, 49.39; H, 3.09; $\mathrm{N}, 14.45 \%$.

\section{Synthesis of reactive dyes $5 a-c$}

A series of dyeing experiments were conducted using three novel reactive dyes listed in Table 1. The dyes 3a-c were prepared as described below.

Table. 1: New synthesized reactive dyes

Dye

2,4,6-Trichloro-s-triazine $(9.4 \mathrm{~g}, 0.051 \mathrm{~mol})$ in acetone $(10 \mathrm{~mL})$ and crushed ice $(10-20 \mathrm{~g})$, was added slowly to a solution of freshly purified 1hydroxy-2-arylazo-7-aminonaphthalene-3-sulfonic acid, prepared above, in distilled water $(100 \mathrm{~mL})$, at below $5^{\circ} \mathrm{C}$, and at pH 5-6 (Scheme 2).
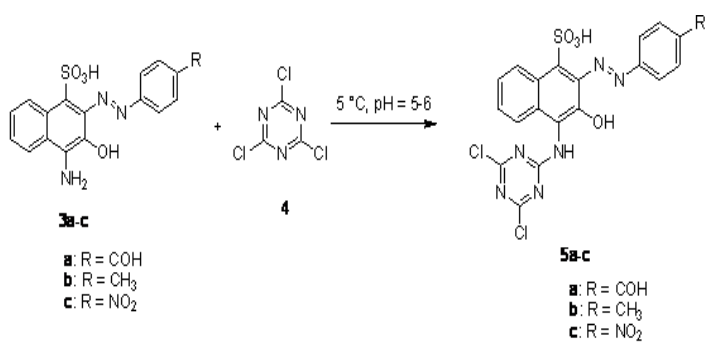

Scheme. 2. Synthesis of reactive dyes 5a-c
The mixture was stirred for $30 \mathrm{~min}$. at $\mathrm{pH} 6.5$ with control by TLC and the resulting red orange product, 1-hydroxy-2-arylazo-7-(2,4-dichlorotriazin-6-ylamino-) naphthalene-3-sulphonic acid, collected by filtration. For purification, the product was dissolved in distilled water $(100 \mathrm{~mL})$ and re-isolated by slow addition of potassium chloride $(20 \% \mathrm{w} / \mathrm{v})$. Dueto the known instability of dichlorotriazines, the product was used direct without further characterization.

The structural of this dyes product was determined by FT-IR, mass spectroscopy, elemental analyses measurements. The band at $730 \mathrm{~cm}^{-1}$ was due to the stretching band of $\mathrm{C}-\mathrm{Cl}$ group.

4-(4,6-Dichloro-[1,3,5]triazin-2-ylamino)-2-(4formyl-phenylazo)-3-hydroxy naphthalene-1sulfonic acid 5 a

Yield (95\%), orange solid. m.p $300^{\circ} \mathrm{C}$. Anal. Calcd. For $\mathrm{C}_{20} \mathrm{H}_{12} \mathrm{C}_{12} \mathrm{~N}_{6} \mathrm{O}_{5} \mathrm{SC}, 46.26 ; \mathrm{H}, 2.33 ; \mathrm{N}, 16.18 \%$; Found C, C, 46.23; H, 2.40; N, 16.14\%. IR (KBr) n cm-1: 730 , 1550. HRMS Calcd. for $\mathrm{C}_{20} \mathrm{H}_{12} \mathrm{C}_{12} \mathrm{~N}_{6} \mathrm{O}_{5} \mathrm{~S} 517.9967$. Found 517.9960 .

4-(4,6-Dichloro-[1,3,5]triazin-2-ylamino)-3hydroxy-2-p-tolylazo-naphthalene-1-sulfonic acid $5 b$

Yield (96\%), red solid. m.p $300^{\circ} \mathrm{C}$. Anal. Calcd. For $\mathrm{C}_{20} \mathrm{H}_{14} \mathrm{Cl}_{2} \mathrm{~N}_{6} \mathrm{O}_{4} \mathrm{~S}: \mathrm{C}, 47.54 ; \mathrm{H}, 2.79 ; \mathrm{N}$, $16.63 \%$; Found C, 47.51; H, 2.83; N, 16.67\%. IR $(\mathrm{KBr}) \mathrm{n}_{\mathrm{cm}}^{-1}$ : 730, 1550. HRMS Calcd. for $\mathrm{C}_{20} \mathrm{H}_{14} \mathrm{Cl}_{2} \mathrm{~N}_{6} \mathrm{O}_{4} \mathrm{~S}$ 504.0174. Found: 504.0168.

4-(4,6-Dichloro-[1,3,5]triazin-2-ylamino)-3hydroxy-2-(4-nitro-phenylazo)-naphthalene-1sulfonic acid $5 \mathrm{c}$

Yield $(90 \%)$, orange solid. m.p $300^{\circ} \mathrm{C}$. Anal. Calcd. For $\mathrm{C}_{19} \mathrm{H}_{11} \mathrm{C}_{12} \mathrm{~N}_{7} \mathrm{O}_{6} \mathrm{SC}, 42.55 ; \mathrm{H}, 2.07 ; \mathrm{N}, 18.28 \%$; Found C, 42.59; H, 2.03; N, 18.25\%. IR (KBr) $\mathrm{n}_{\mathrm{cm}}^{-1}: 730$, 1550. HRMS Calcd for $\mathrm{C}_{19} \mathrm{H}_{11} \mathrm{C}_{12} \mathrm{~N}_{7} \mathrm{O}_{6} \mathrm{~S} 534.9869$. Found 534.9858.

\section{Dyeing}

An Ahiba dyeing machine was used to dye polyamide fabric, at a liquor ratio of 20:1. Dyeing experiments were carried out at a depth of shade of $1 \%$ o.m.f, at different $\mathrm{pH}$ values (2-10), for different durations (40-60 min.) and at different temperatures $\left(80-98{ }^{\circ} \mathrm{C}\right)$. At the end of the dyeing, fabric was removed and rinsed in cold tap water for 5 minutes. 


\section{Colour strength}

The colour yield of dyed samples was evaluated by light reflectance mesearements using SF 300 spectrophotometer. Relative colour strengths (K/S values) were determined using the KubelkaMunk equation ${ }^{10}$

\section{Dye exhaustion}

The extent of dye exhaustion (\%E) was determined spectrophotometrically. The percentage dye bath exhaustion (\%E) was calculated from Eq. (1), where $A_{0}$ and $A_{1}$ are, respectively, the absorbance of the dye bath before and after dyeing.

$\% E=\left(A_{0}-A_{1}\right) * 100 / A_{0}$

\section{Dye fixation}

In order to determine the degree of dye fixation the following procedure was used:

A sample (1 $\mathrm{g}$ ) of dyed fabric was immersed in $150 \mathrm{ml}$ of $20 \%$ aqueous pyridine solution, the temperature was raised rapidly to boiling and treatment continued under reflux until no further dye was removed from the fiber, this took approximately 3 hours. The stripped dyeing was thoroughly rinsed in tap water and allowed to dry at room temperature. The percentage of exhausted dye which fixed was determined from Eq. (2), where (K/ $\mathrm{S})_{1}$ and $(\mathrm{K} / \mathrm{S})_{2}$ represent respectively the colour strength of the dyeing fabric before and after stripping ${ }^{11,12}$.

$\% \mathrm{~F}=(\mathrm{K} / \mathrm{S})_{1} /(\mathrm{K} / \mathrm{S})_{2}{ }^{*} 100$

\section{Visible absorption spectra of dyes}

Visible absorption spectra were recorded using a Philips model PU UV/visible spectrophotometer.

\section{Fastness testing}

The dyed samples were tested for fastness properties according to standard methods, the specific tests were for colour fastness to washing ISO 105-C02:1989 and colour fastness to rubbing ISO 105-X12:1987.

\section{RESULTS AND DISCUSSION}

\section{Visible absorption spectra of dyes}

The dyes are red orange and the wavelengths of maximum absorption varied from 470 to $500 \mathrm{~nm}$ (Tab 2). The bathochromic shift and the highest extinction coefficient of the dye $5 \mathrm{~b}$ is due to the common effect of electron donating groups, which is $\mathrm{CH}_{3}$ in our case ${ }^{13,14}$.

\begin{tabular}{ccc}
$\begin{array}{c}\text { Table. 2: Extinction coefficient and wavelength } \\
\text { of maximum absorbance, of novel reactive } \\
\text { dyes }\end{array}$ \\
\hline Dye & $\lambda_{\max }(\mathrm{nm})$ & $\varepsilon_{\max }\left(\mathrm{mol}^{-1} \mathbf{c m}^{-1} \mathrm{~L}\right)$ \\
\hline $5 a$ & 488 & 20050 \\
$5 b$ & 500 & 22550 \\
$5 c$ & 470 & 19110 \\
\hline
\end{tabular}

\section{Effect of $\mathrm{pH}$ on the dyeing results}

The effect of the $\mathrm{pH}$ value on the dyeing result have been studied. Results are collected in table 3. It was shown that the $\mathrm{pH}$ parameters affect enormously the dyeing results. Optimal dyeing results was registered at lowest $\mathrm{pH}$ value (in a $\mathrm{pH}$ range from 2 to 4 ), and then at a higher $\mathrm{pH}$ value, a decrease in the exhaustion level, the fixation level and also in the depth of shade have been observed.

Knowing that depending on the acidity of the medium, the polyamide fabric may be present under one of the forms present in figure 3 , and that

Table. 3: Effect of $\mathrm{pH}$ on the dyeing results. Dyeing parameters: LR 20:1; $60 \mathrm{~min} ; 98^{\circ} \mathrm{C}$

\begin{tabular}{lccccccccc}
\hline pH & $\begin{array}{c}5 \mathbf{a} \\
\text { E\% }\end{array}$ & E\% & F\% & K/S & $\begin{array}{c}\text { 5b } \\
\text { F\% }\end{array}$ & K/S & E\% & F\% & K/S \\
\hline 2 & 94.30 & 91.25 & 80.55 & 5.93 & 85.26 & 6.00 & 96.40 & 93.92 & 7.78 \\
4 & 94.34 & 93.99 & 90.85 & 6.44 & 92.08 & 70.25 & 96.75 & 95.04 & 7.92 \\
6 & 82.82 & 66.50 & 48.21 & 2.59 & 77.39 & 3.10 & 88.65 & 72.51 & 4.03 \\
8 & 50.21 & 45.06 & 31.90 & 1.36 & 34.47 & 1.26 & 58.52 & 53.03 & 2.06 \\
10 & 35.00 & 33.80 & 29.90 & 0.79 & 31.40 & 0.92 & 37.00 & 34.50 & 1.88 \\
\hline
\end{tabular}


the different forms are present in an equilibrium state, ${ }^{15}$ this make the explication of the dyeing result more trivial. Indeed, in acidic medium a nucleophilic substitution reaction occur between the nonprotonated amino end group of polyamide fibre and the chloro group of the dyes. Also, protonated amino group, which can be present in polyamide in acidic medium, can electrostatically react with the sulfonate group of the dye.

Then, increasing in $\mathrm{pH}$ value up to 6 promotes the formation of protonated amino end group of fiber and disadvantage the nucleophilic substitution reaction. Consecutively a decrease in a depth of shade and also in the overall dyeing parameters have been observed. At basic medium, electrostatic repulsion can be developed between the terminal carboxylate group of the fiber and the sulphonate group of the dyes, this make the K/S value so low.

Also, comparison of the studied dyeing parameters for this series of dyes show that the highest level of the dye exhaustion and fixation was registered with the dye $5 c$, then $5 a$ and then $5 b$. Thus, more the withdrawing electron effect of the attached group is important, more the dyeing results are better. Indeed, it was proved that the withdrawing electron group involve the chargetransfer interactions between the aryl group of the dye and carbonyl groups of the fibre. This property promotes the reaction of nucleophilic substitution and enhance consecutively the dyeing results ${ }^{15}$.

\section{Effect of temperature on the dyeing results}

The effect of the temperature of dyeing has been studied. Results are collected in table 4 . It was shown that increasing the temperature of dyeing from 80 to $98^{\circ} \mathrm{C}$ improves the dyeing results for all the series of dyes. However, it was observed that the effect of increasing temperature was more pronounced for the dye $5 \mathrm{~b}$, then $5 \mathrm{a}$, and then $5 \mathrm{c}$ and that optimal results were observed at lowest temperature for the dye $5 \mathrm{c}$ and $5 \mathrm{a}$. Those results are reported to the effect of withdrawing electron group in those dyes.

Indeed, as previously mentioned, the withdrawing electron group involves the chargetransfer interactions between the aryl group of the dye and carbonyl groups of the fiber which facilitates the dyeability of polyamide.

\section{Effect of dyeing time}

Dyeing time was varied from 40 to 60 minutes. Results were assembled in table 5 . It was observed that withdrawing electron group in dyes $5 \mathrm{c}$ and $5 \mathrm{a}$ accelerate the dye bath exhaustion when comparing with the dye $5 \mathrm{~b}$. Also the charge transfer interaction developed between the aryl group of the dye and carbonyl groups of the fibre, due to the withdrawing electron group, accelerate the reaction of nucleophilic substitution and enhance the fixation level from 40 minutes.

\section{Fastness properties of dyed fabric}

The rating of fastness properties (washing, and rubbing fastness) of all the dyed polyamide fabric was about 5 .

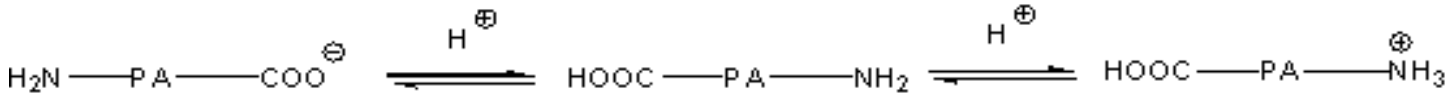

Fig. 3. Protonation's Equilibrium of nylon with varying acidity

Table. 4: Effect of temperature on the dyeing results. Dyeing parameters: LR 20:1; $60 \mathrm{~min}$; pH 4

\begin{tabular}{lccccccccc}
\hline $\begin{array}{l}\text { Temperature } \\
\left({ }^{(} \mathbf{C}\right)\end{array}$ & $\begin{array}{c}\mathbf{5 a} \\
\text { E\% }\end{array}$ & F\% & K/S & E\% & $\begin{array}{c}\text { Fo } \\
\text { F\% }\end{array}$ & K/S & E\% & F\% & K/S \\
\hline 80 & 81.5 & 80.02 & 5.49 & 79.12 & 79.00 & 4.85 & 82.53 & 81.57 & 5.71 \\
85 & 89.5 & 86.12 & 6.20 & 87.44 & 85.72 & 5.50 & 92.62 & 86.96 & 7.15 \\
90 & 94.12 & 89.67 & 6.98 & 89.65 & 87.36 & 6.09 & 94.10 & 88.96 & 7.61 \\
98 & 94.34 & 92.08 & 7.25 & 93.99 & 90.85 & 6.44 & 96.75 & 95.04 & 7.92 \\
\hline
\end{tabular}




\section{Luminescent on polyamide fiber}

Fig. 4 shows optical image of the solid dye $5 a$ and dyed nylon under UV light with their characteristic strong brown.

The fluorescence emission spectrum of the dyed nylon with dye $5 \mathrm{a}$ was determined at $488 \mathrm{~nm}$ excitation.
Photoluminescence spectra of the dyed nylon with dye $5 a$ in the spectral range of $580-700$ $\mathrm{nm}$ with excitation at $488 \mathrm{~nm}$ are presented in Fig. 5 . A characteristic emission band of dyed nylon was observed at $625 \mathrm{~nm}$ with strong red orange emission color.

Table. 5: Effect of dyeing time. Dyeing parameters: LR 20:1; $98^{\circ} \mathrm{C}$; $\mathrm{pH} 4$

\begin{tabular}{lccccccccc}
\hline $\begin{array}{l}\text { Time } \\
\text { (min.) }\end{array}$ & $\begin{array}{c}\text { 5a } \\
\text { E\% }\end{array}$ & F\% & K/S & E\% & $\begin{array}{c}\text { 5b } \\
\text { F\% }\end{array}$ & K/S & E\% & F\% & K/S \\
\hline 40 & 92.17 & 89.91 & 6.51 & 85.13 & 81.01 & 5.54 & 94.78 & 91.78 & 7.54 \\
50 & 94.06 & 94.50 & 7.05 & 89.85 & 87.56 & 6.03 & 95.8 & 93.56 & 7.80 \\
60 & 94.34 & 92.08 & 7.25 & 93.99 & 90.85 & 6.44 & 96.75 & 95.04 & 7.92 \\
\hline
\end{tabular}<smiles>O=C(O)c1ccc(N=Nc2c(O)c(Nc3nc(Cl)nc(Cl)n3)c3ccccc3c2S(=O)(=O)O)cc1</smiles>

5

Fig. 4. Intense photoluminescence of brown dye 5 a on nylon was observed under UV illumination $(\lambda 365 \mathrm{~nm})$

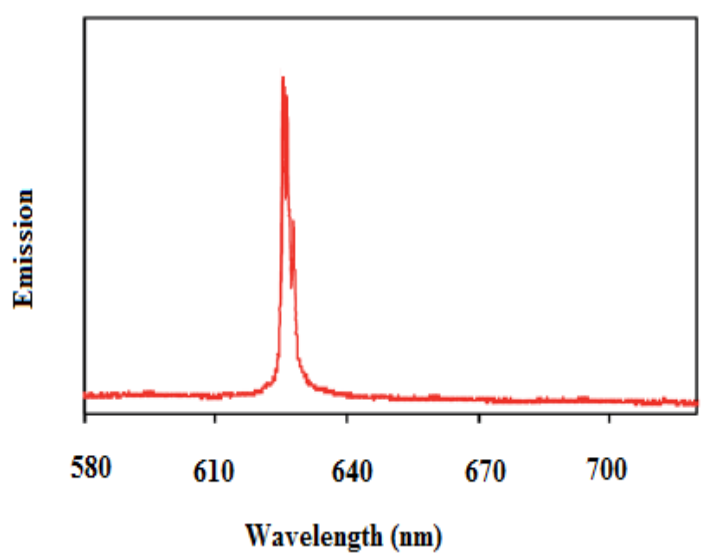

Fig. 5. Photoluminescence spectra of dye 5 a grown on polyamide fiber

\section{CONCLUSION}

All the Synthesized dyes presented the highest exhaustion level on polyamide at $\mathrm{pH} 4$. Withdrawing group attached to the dye structure increase the dye exhaustion and the fixation level. The study of the dyeing temperature and time has been developed, and it was shown that the withdrawing electron groups promotes the reaction of nucleophilic substitution and enhance consecutively the dyeing results at lowest time and temperature. Washing and rubbing fastness properties of all the dyed samples were good. Under UV excitation, the dyed polyamide display intense orange red emission color. 


\section{ACKNOWLEDGEMENT}

This work was supported by the Textile

Engineering Laboratory, Higher Institute of
Technological Studies of Ksar Hellal, University of Monastir, Tunisia.

\section{REFERENCES}

1. Burkinshaw, S.M.; Son Young, A.; Bide, M. J. Dyes Pigments, 2001, 48, 245.

2. Remington, W.R.; Gladding, E.K. J. Am. Chem. Soc., 1950, 72, 2553.

3. Broadbent, A.D. Basic principles of textile coloration: Society of Dyers and Colourists, Bradford. 2001.

4. Burkinshaw, S.M.; Chevli, S.N.; Marfell, D.J. Dyes Pigments 2000, 45, 235.

5. Ginns, P.; Silkstone K. In: Nunn D.M. editor. The dyeing of synthetic e polymer and acetate fibres. The Dyers Company Publications Trust 1979.

6. Kim, S.D.; Choi, Y.J.; Lee, H.Y.; Lee, J.L. Fibers and Polymers, 2012, 13, 199.

7. Soleimani, G.A.;Taylor, J.A. Coloration Technology, 2011, 127, 227.

8. Youssef, Y.A.; Mousa, A.A.; Farouk, R.; Allam, E.E.; El-Kharadly, E.A. Coloration Technology,
2007, 123, 312.

9. Renfrew, A.H.M. Reactive dyes for textile fibres: Society of Dyers and Colorists, Bradford 1999.

10. Judd D.B., Wysezcki, G. Colour in Business, Science and Industry, John Wiley \& Sons, New York, NY, USA 1975.

11. Lewis, D.M. Wool dyeing: Society of Dyers and Colourists, Bradford. 1992.

12. Burkinshaw, S.M. Chemical principles of synthetic fibre dyeing: Chapman \& Hall, London 1995.

13. Uscumlic, G.S.; Petrovic, S.D. Indian Journal of Chemistry, 2002, B 41, 206.

14. William, J.L.; Jo-Ann, H.; Banisch, M.S.; Workentin, J. J. Chem. Soc., Chem. Commun., 1993, 988.

15. Soleimani, G.A.; Taylor, J.A. Dyes and Pigments, 2008, 76, 610. 